\title{
Engineering Fiber Volume Fraction of Natural Fiber Staple - Spun Yarn Reinforced Composite
}

EI Messiry $\mathbf{M}^{*}$ and EL Deeb R

Textile Engineering Department, Faculty of Engineering, Alexandria University, Egypt

\begin{abstract}
There is a large demand for high fiber volume fraction natural fiber reinforcement polymer composites. Among many parameters affecting the mechanical properties of a composite, the fiber volume fraction is the most decisive factor. The effect of fiber volume fraction on the physical and tensile properties of aligned natural fiber staple spun yarn composites has been intensively investigated. However, there have been no direct studies on determining the relation between composite fiber volume fraction and the yarn fiber volume fraction for fiber staple-spun yarn composite. With the intention to improve the utilization of most fibers of the yarn cross section in the composite, the variation of the yarn diameter in staple-spun yarn reinforced composite is investigated in this study. The analysis of the yarn diameter indicates that it has a high variability that necessitates an increase in the composite diameter to envelope all the yarn body leading to reduction in its fiber volume fraction. A model for the determination of composite fiber volume fraction was driven, grounded on the analysis of the yarn diameter variability along its length. An equation has also been developed to calculate the diameter of the composite to cover majority of yarn cross section.
\end{abstract}

Keywords: Fiber composites; fiber volume fraction; Thermoplastic polymer; Composite fiber volume fraction

\section{Introduction}

Renewable bio-based composite materials provide a stimulating prospect to develop sustainable materials. Natural fibers in particular are an attractive source of reinforcement for fiber reinforced plastics. The low density, low cost of raw material, high specific properties and ecological profile of plant fibers has portrayed them as a prospective replacement for E-glass in traditional fiber reinforced polymer [1].

One of the many advantages of composite materials, in general is the possibility of tailoring material properties to meet different requirements. It is well-known that the macroscopic behavior of heterogeneous fiber reinforced polymer depends on many factors; including the (volumetric) composition, the stress-strain behavior of each component, the geometrical arrangement of the phases and the interface properties [1,2]. Composites can be made with fibers as mats and as aligned assemblies impregnated with matrix polymer $[3,4]$.

Aligned fibers composites are generally stronger and stiffer in the fiber direction than composites with randomly orientated fibers. Consequently, the aligned yarns composites have higher strength than woven and mat one [1]. The fabrication route of the aligned plant fiber yarn composites is aligned by filament-winding $[3,5]$.

The staple fibers in a conventional twisted yarn are held together by the fiber-to-fiber friction and produced on the different spinning systems. The flax yarn fibers in the present study show very good reinforcement efficiency with a tensile strength and modulus [6].

The fiber volume fraction of fiber reinforced composite directly correlated with the mechanical properties of the composite. The ability of composites reinforced with short fibers to support loads depending on the presence of the matrix as the load-transfer an intervening substance, and the efficiency of this load transfer is directly related to the ratio of the fiber/matrix. Given the fiber volume fraction, the theoretical elastic properties of a composite can be determined. The elastic modules of a composite can be expressed as:

$$
\boldsymbol{E}=\left(1-\boldsymbol{V}_{f}\right) \boldsymbol{E}_{\boldsymbol{m}}+\boldsymbol{V}_{f} \boldsymbol{E}_{f}
$$

Where:
$V_{f}$ is the fiber volume fraction.

$E_{m}, E_{m}$ is the elastic modulus of matrix and fiber, respectively.

The value of the volume fraction varied depending on the structure of reinforcement: unidirectional, woven, or random mat. Therefore, there is an optimal space between fibers that will fully exploit the uniform load transfer between fibers [1]. Minimum and critical fiber volume fraction, if there are very few fibers present $\left(0<\mathrm{V}_{\mathrm{f}}<\mathrm{V}_{\mathrm{f} \text {,min }}\right)$, the stress on a composite may be high enough to break the fibers. The broken fibers, which carry no load, can be then regarded as an array of aligned holes $(0<\mathrm{Vf}<\mathrm{Vf}$,min) [7].

The reinforcing action of the fibers is only observed once the fiber volume fraction exceeds the critical fiber volume fraction $\left(\mathrm{V}_{\mathrm{f}}>\mathrm{V}_{\mathrm{f}, \mathrm{crit}}\right)$. Which implicitly illustrates the minimum and critical fiber volume fractions for short banana fiber reinforced vinyl-ester composites to be $\mathrm{V}_{\mathrm{f} \text {,min }} \cong 15 \%$ and $\mathrm{V}_{\mathrm{f}, \mathrm{crit}} \cong 25 \%$ [8]. As the theoretical maximum fiber volume fraction of flax and jute composites is known, the maximum theoretical tensile modulus can be determined. This is found to be $17.3 \mathrm{GPa}$ for flax-polyester (at $\mathrm{V}_{\mathrm{f}}=33.1 \%$ ) [9], for jute-polyester (at $\mathrm{V}_{\mathrm{f}}=46.8 \%$ ). A high $\mathrm{V}_{\mathrm{f} \text {, crit }}$ (of the order of $10 \%$ ) and low $\mathrm{V}_{\mathrm{f} \text {,max }}$ (of the order of 45\%) implies that the range of useful fiber volume fractions for vacuum infused PFCs containing staple fiber twisted yarns is only $35 \%$.

As the theoretical maximum fiber volume fraction of flax and jute composites is known, the maximum theoretical tensile strength can be determined [10].

*Corresponding author: Magdy El Messiry, Textile Engineering Department Faculty of Engineering, Alexandria University, Egypt, Tel: 2035910052; E-mail: mmessiry@yahoo.com

Received November 07, 2016; Accepted November 22, 2016; Published December 02, 2016

Citation: El Messiry M, EL Deeb R (2016) Engineering Fiber Volume Fraction of Natural Fiber Staple - Spun Yarn Reinforced Composite. J Textile Sci Eng 6: 278. doi: 10.4172/2165-8064.1000278

Copyright: () 2016 El Messiry M, et al. This is an open-access article distributed under the terms of the Creative Commons Attribution License, which permits unrestricted use, distribution, and reproduction in any medium, provided the original author and source are credited. 
Many researchers analyzed the value of the yarn fiber volume fraction in the spun yarns [11-13], either theoretically or experimentally. The fiber distribution in the yarn cross section was found to be varied in the radial direction. The structure of the spun yarn the fibers distribution in its cross section is different [2].

The theoretical distribution of the fibers in the yarn cross section may be assumed hexagonal or square, giving different values of packing density. The yarn packing density is also a function of the yarn twist level [13]. Semi-empirical relationship between twist level T (turns per meter) and fiber packing density of staple fiber yarns indicates that its value increased with the increase of twist level. The effect of fiber twist on the tensile properties of single sisal yarns was investigated. It was shown that lower twist level led to higher mechanical properties of its reinforced composite because the polymer matrix provides enough bonding force between sisal fibers in the impregnated yarn, the low twist sisal yarn with a low twist angle would possess better tensile properties [13].

In practical cases, there is a variation in fiber diameter and irregular fiber packing increases the difficulty in calculating the $\mathrm{V}_{\text {f.comp }}$ without apprehension the different variables existing along the yarn length.

The objectives of this work are to give a method of calculating the fiber volume fraction of composite taking into consideration the actual variation of the yarn diameter to accomplish suitable structural performance for a composite material. The fiber volume ratio plays a critical role.

\section{Material and Methods}

\section{Material}

Sets of different yarns were spun on ring spinning with specifications given in Table 1.

\section{Yarn diameter measurement}

Most of the researchers consider the yarn diameter is constant, which is true only in the case monofilament or multi-filament yarns. Several ring spun yarns were produced and the diameters were measured on Quick Quality management QQM3 instrument in this study, Faculty of Textiles lab, The Technical University of Liberec, CZ. The QQM has 2 Optical sensors of $2 \mathrm{~mm}$ width, equipped with infra diodes and transistors positioned in the direction of yarn delivery, the value of yarn diameter, $2 \mathrm{~mm}$ apart, is recorded at the sampling rate $300 \mathrm{~m} / \mathrm{min}$ [4]. Quick Quality management QQM3 instrument makes it possible to get the individual data of yarn diameter. Also, the yarns were tested on Uster 4 for characterization of yarn evenness and yarn diameter. Table 2 gives the results of the tested yarns.

\section{Results and Discussion}

\section{Fiber volume fraction}

In the case of continuous filament yarns, the impregnation is defined here in order to saturate every single reinforcement filament by the molten thermoplastic polymer. The molten thermoplastic flows through the capillaries between the reinforcement filaments [13].

In this case the fiber volume fraction:

\begin{tabular}{|c|c|c|c|c|c|c|c|c|c|}
\hline Yarn ID & Yarn count tex & tpm & Spinning system & Material & Yarn ID & Yarn count tex & tpm & Spinning system & Material \\
\hline 6394 & 24.6 & 744.64 & Carded & Cotton & 6402 & 29.5 & 661.88 & Carded \\
\hline 6395 & 24.6 & 705.45 & Carded & Cotton & 6403 & 29.5 & 643.99 & Carded & Cotton \\
\hline 6396 & 10.9 & 1146.36 & Combed & Cotton & 6404 & 19.7 & 766.81 & Carded & Cotton \\
\hline 6397 & 10.9 & 1175.76 & Combed & Cotton & 6405 & 19.7 & 722.99 & Carded & Cotton \\
\hline 6398 & 19.7 & 876.36 & Combed & Cotton & 6406 & 19.7 & 701.08 & Combed & Cotton \\
\hline 6399 & 19.7 & 898.26 & Combed & Cotton & 6407 & 24.6 & 764.24 & Carded & Cotton \\
\hline 6400 & 14.8 & 885.44 & Combed & Cotton & 6408 & 24.6 & 666.26 & Carded & Cotton \\
\hline 6401 & 14.8 & 885.44 & Combed & Cotton & 6409 & 24.6 & 685.86 & Carded & Cotton \\
\hline
\end{tabular}

Table 1: Yarn specifications.

\begin{tabular}{|c|c|c|c|c|c|c|c|c|c|c|c|}
\hline Yarn ID & CV [\%] & CV (1 m) [\%] & CV (3 m) [\%] & $\varphi$ 2D [mm] & $\begin{array}{l}\text { CV1D 0,3 } \\
\text { mm [\%] }\end{array}$ & $\begin{array}{l}\text { CV2D 0,3 } \\
\mathrm{mm}[\%]\end{array}$ & $\begin{array}{c}\text { CV2D } 8 \mathrm{~mm} \\
{[\%]}\end{array}$ & s2D mm & $\mathbf{H}$ & sH & $\begin{array}{c}\text { Neps }+140 \%[1 / \\
\text { km }]\end{array}$ \\
\hline 6394 & 13.55 & 3.83 & 3.16 & 0.277 & 16.88 & 15.26 & 11.89 & 0.031 & 6.43 & 1.39 & 310 \\
\hline 6395 & 12.86 & 3.56 & 2.94 & 0.274 & 16.5 & 14.44 & 11.23 & 0.031 & 6.37 & 1.47 & 170 \\
\hline 6396 & 13.27 & 3.34 & 2.38 & 0.15 & 17.19 & 15.9 & 11.4 & 0.018 & 4.74 & 1.17 & 630 \\
\hline 6397 & 13.11 & 3.77 & 2.78 & 0.151 & 16.76 & 15.44 & 11.16 & 0.017 & 4.65 & 1.17 & 490 \\
\hline 6398 & 14.91 & 4.31 & 3.71 & 0.218 & 19.82 & 18.68 & 13.4 & 0.027 & 6.21 & 1.55 & 1620 \\
\hline 6399 & 14.72 & 4.73 & 3.69 & 0.213 & 19.07 & 17.43 & 12.88 & 0.027 & 6.01 & 1.56 & 1005 \\
\hline 6400 & 15.79 & 3.97 & 2.96 & 0.182 & 19.3 & 17.77 & 13.55 & 0.025 & 5.05 & 1.28 & 1365 \\
\hline 6401 & 16.07 & 4.56 & 3.38 & 0.184 & 19.73 & 13.84 & 18.01 & 0.024 & 5 & 1.3 & 1220 \\
\hline 6402 & 14.45 & 4.47 & 2.97 & 0.282 & 17.85 & 16.23 & 12.5 & 0.033 & 6.45 & 1.5 & 410 \\
\hline 6403 & 14.72 & 4.86 & 3.73 & 0.28 & 18.43 & 16.45 & 12.74 & 0.035 & 6.42 & 1.56 & 555 \\
\hline 6404 & 13.99 & 3.35 & 2.37 & 0.249 & 17.61 & 15.47 & 12.3 & 0.031 & 5.51 & 1.5 & 560 \\
\hline 6405 & 14.64 & 4.27 & 3.51 & 0.26 & 18.76 & 16.69 & 12.94 & 0.033 & 7.21 & 1.65 & 805 \\
\hline 6406 & 15.12 & 4.71 & 3.93 & 0.264 & 19.36 & 16.81 & 13.17 & 0.033 & 7.12 & 1.69 & 640 \\
\hline 6407 & 12.72 & 3.09 & 2.2 & 0.253 & 15.3 & 13.44 & 10.7 & 0.026 & 4.89 & 1.22 & 180 \\
\hline 6408 & 13.33 & 4.39 & 3.81 & 0.251 & 15.74 & 13.45 & 10.8 & 0.028 & 4.82 & 1.25 & 225 \\
\hline 6409 & 13.39 & 3.88 & 2.92 & 0.275 & 16.41 & 14.25 & 11.26 & 0.03 & 5.95 & 1.41 & 210 \\
\hline
\end{tabular}

Table 2: The analysis of the yarn evenness, yarn diameter and hairiness of the samples. 


$$
V_{f \text { comp }}=\frac{V_{f}}{\left(V_{c}\right)} .
$$

Where $V_{f}$ and $V_{m}$ are the volumes of the fibers and matrix, respectively.

The fiber volume can be calculated for a circular shape of the fibers and composite, as illustrated in Figure 1, by:

$$
\begin{aligned}
& V_{f}=0.785 n_{f} D_{f}^{2} \\
& V_{c}=0.785 D_{c}^{2} \\
& V_{f \text { comp }}=\frac{n_{f} D_{f}^{2}}{D_{c}^{2}} .
\end{aligned}
$$

Where; $n_{f}$ is the number of reinforcement fibers, $D_{f}{ }^{2}$ and $D_{c}^{2}$ are the fiber diameter and composite diameter (Figure 1).

\section{Spun yarn diameter}

Actually, in the structure of the spun yarn the fiber's distribution in its cross section is different (Figure 2). Besides to that, the variation of the yarn diameter along the yarn length which add another variability to the value of $V_{f}$ (Figure 2).

The yarn diameter of natural fiber spun yarn was varied along its length due to the variation of the number of fibers in the yarn cross section, especially in the case of the bast fibers which are widely used in the manufacturing of nature fiber polymer composites. The variation of yarn diameter along the yarn length is illustrated in Figure 3.

The histogram of the yarn diameter is shown in Figure 4, indicating that in most of the cases the frequency curve is skewed to the right with the high value of kurtoses (Figure 4).

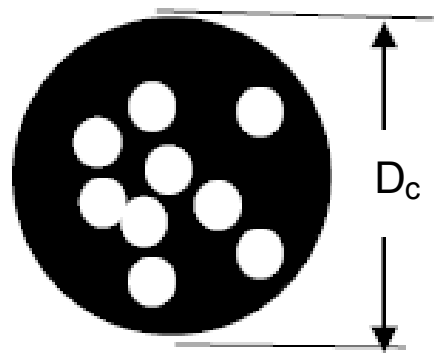

Figure 1: Sketch of composite cross section

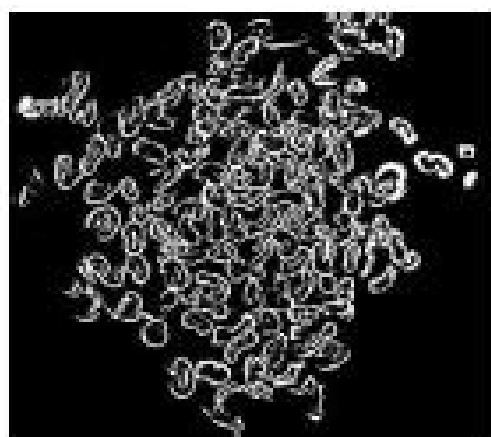

Figure 2: Fiber distribution in the yarn cross section.

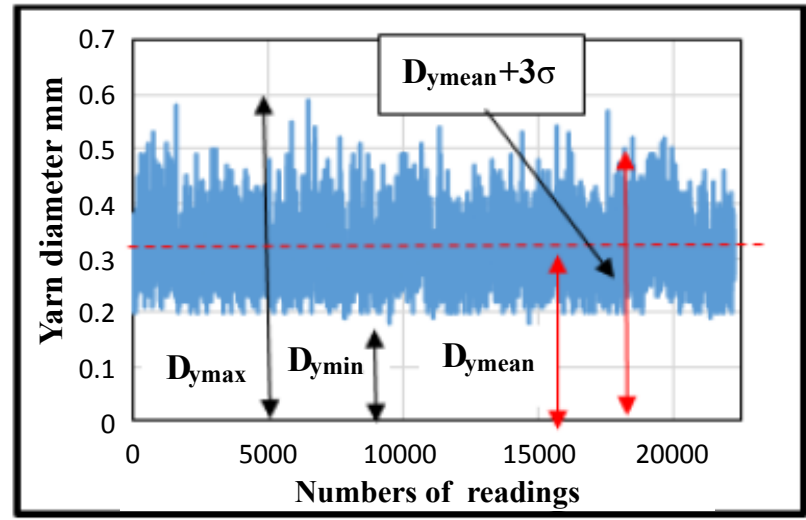

Figure 3: Yarn diameter.

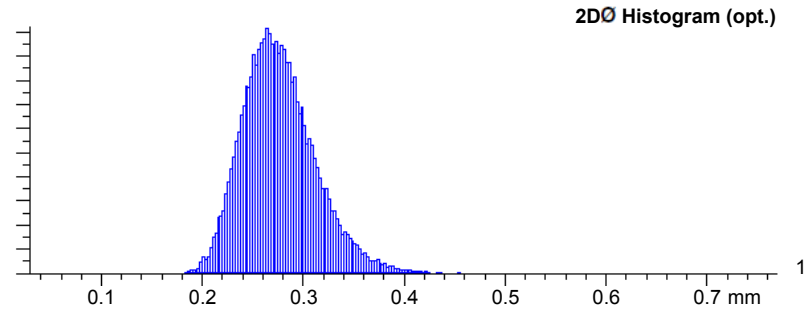

Figure 4: The histogram of the yarn diameter ID 06394.

Moreover, the value of the yarn fiber volume fraction $V_{f}$ is found to vary across the yarn cross section [2]. So, the composite fiber volume will also vary, even the composite diameter is constant. The yarn volume fraction depends on the spinning system, twist level (turns per meter), yarn count, and fiber count [2] (Figure 5).

The yarn diameter data measured on Quick Quality management QQM3 instrument was analyzed and given in Figure 5. Which indicates the mean diameter of the yarn cannot be used for determined final composite diameter since large number of fibers will be outside the surface limit. Further, the number of the sections which has large diameter values varied from one yarn to the other. Consequently, the diameter of the composite that required to cover most of the yarn diameters along its length should be predetermined.

\section{Data analysis}

In order to estimate the value of the composite fiber volume fraction, the data of the yarn diameter measured for samples, each $2 \mathrm{~mm}$, along the yarn length. Sample sections 22230 are considered. The total volume of the yarn is calculated $V_{y}$. Assuming the yarn fiber volume fraction $\alpha_{y}$, then the composite fiber volume fraction will be:

$V_{\text {fcomp }}=\alpha_{\mathrm{y}}\left(\mathrm{V}_{\mathrm{y}} / \mathrm{V}_{\text {comp }}\right)$

Where:

$a_{y}$ is fiber volume fraction,

$$
\begin{aligned}
& \mathrm{V}_{\mathrm{y}}=\sum_{0}^{n} \frac{\pi}{4} D_{i}^{2} \Delta l \\
& V_{\text {fcomp }}=\frac{\pi}{4}\left(\left(D_{c}\right)^{2} \sum_{0}^{n} \Delta l,\right.
\end{aligned}
$$



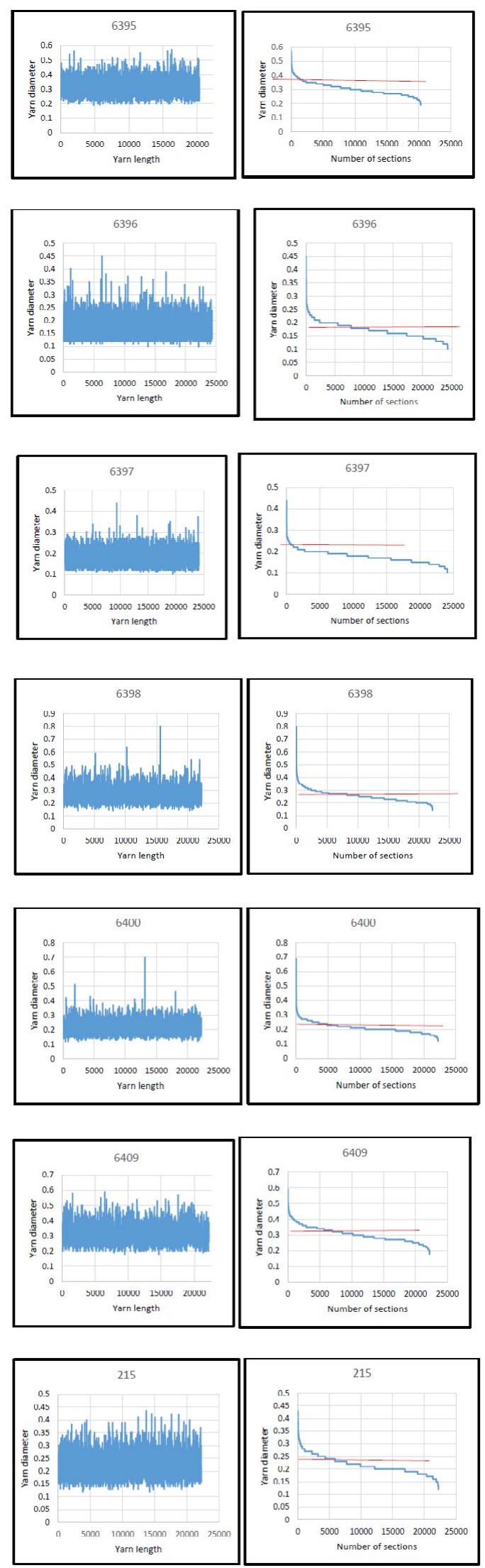
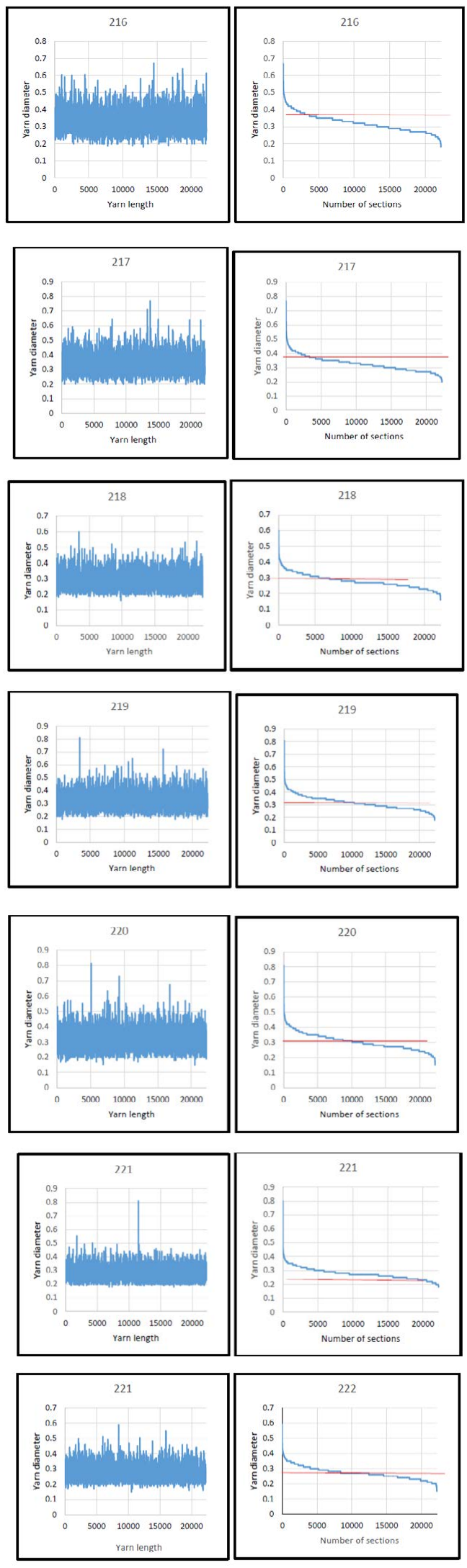

Figure 5: Analysis of the yarn diameter of tested yarns. 
$\mathrm{n}$ is number of the measured sections.

The choice of the composite diameter where consider two cases:

Case I : take $\mathrm{D}_{\text {comp }}=\mathrm{D}_{\mathrm{y} \text { mean }}+3 \sigma$

Case II: take $\mathrm{D}_{\text {comp }}=\mathrm{D}_{\text {ymax }}$

Where: $\mathrm{D}_{\text {ymax }}$ is maximum diameter

$\mathrm{D}_{\text {ymean }}$ is mean yarn diameter

$\sigma$ is the standard deviation of the yarn diameter.

Case study I: The variation of the yarn diameter (Figure 6) indicates that in order to cover the surface of the yarn by the matrix for the benefit of the utilizing all the fibers in the yarn cross section, the diameter should be $0.22 \mathrm{~mm}$ greater than the yarn mean diameter, in this case is $0.328 \mathrm{~mm}$. Which leads to a reduction of the composite fiber volume fraction value? As the diameter of the composite is reduced, a certain percentage of the fibers will not share the load applied to the composite. It is clear that the percentage of the yarn cross section containing the large value of the yarn diameters is very limited. Accordingly, when taking $\mathrm{D}_{\text {comp }}=\left(\mathrm{D}_{\mathrm{y} \text { mean }}+3 \sigma\right)$ will increase the value of composite fiber volume fraction $V_{\text {fcomp }}$ (Figure 6).

The analysis of the yarn diameters of the different measured samples are given in Table 3 .

The value of composite fiber volume fraction, assuming $\mathrm{D}_{\text {comp. }}=\left(\mathrm{D}_{\mathrm{y}}\right.$ $+3 \sigma)$, versus the yarn fiber volume fraction is illustrated in Figure 7 , indicating that in all cases the yarns with the different characteristics result in the lower composite fiber volume fraction, even in the case of when the yarn fiber volume fraction is equal to one. The lower value of composite volume fraction is due to the variation in the yarn diameters at the different cross sections.

As it indicated in Figure 8, the increase of the coefficient of variation of the yarn diameter has an impact on the composite fiber volume fraction (Figures 7 and 8).

Thus, the relation between $V_{\text {fcomp }}$ and $V_{\text {fyarn }}$ depends on the variability of the yarn diameter in the different cross sections of the yarn. The distribution shape of the yarn diameter is expressed by its kurtosis, which is a measure that describes the shape of a distribution's tails in relation to its overall shape and reflects on the value of $V_{\text {fcomp }}$ as illustrated in Figure 9.

In order to reduce the value of kurtosis of the yarn, it's recommended to adjust the setting on the winding machine to remove thick places and long thin places for yarn to be used in composite applications.

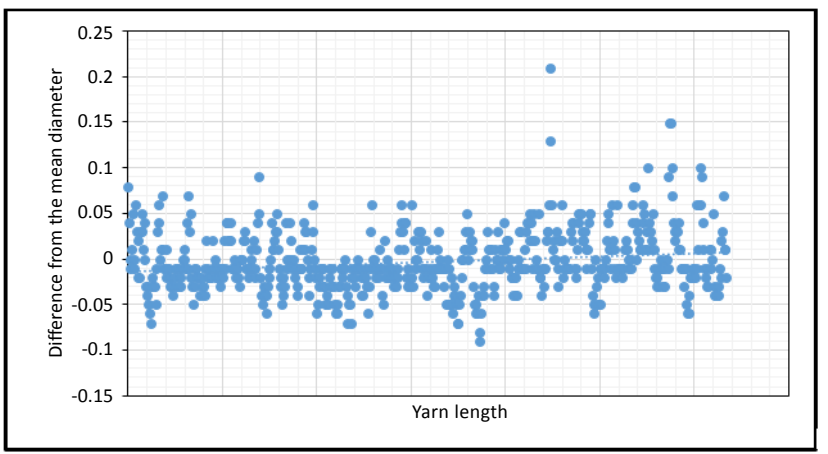

Figure 6: Distribution of the yarn diameter along the yarn length.

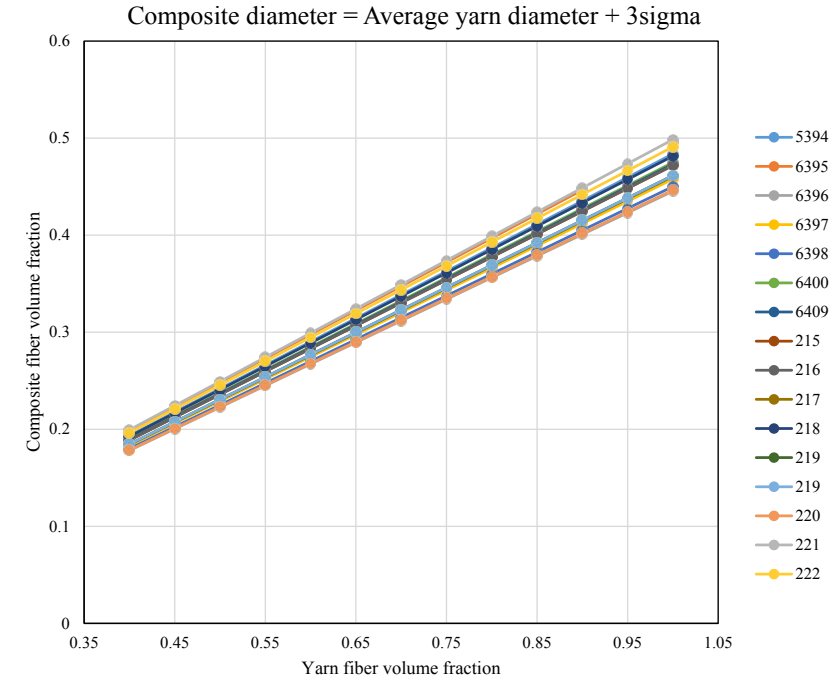

Figure 7: Composite fiber volume fraction versus the yarn fiber volume fraction.

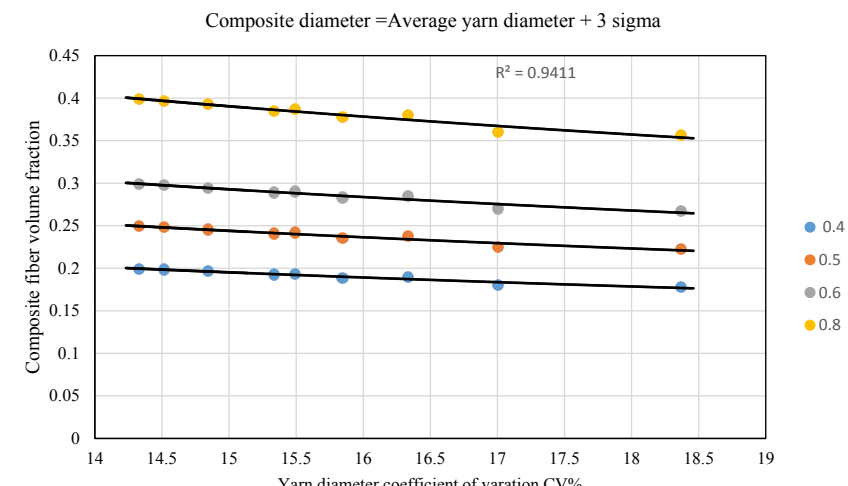

Figure 8: The composite fiber volume fraction versus yarn diameter coefficient of variation.

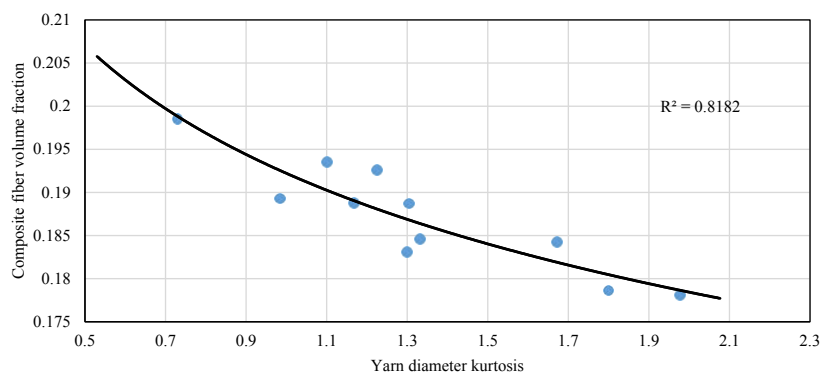

Figure 9: The composite fiber volume fraction versus yarn diameter kurtosis.

Case study II: Assume the composite diameter $\mathrm{D}_{\text {comp }}$ was chosen to cover all the yarn diameters along the yarn length which is its maximum diameter $\mathrm{D}_{\mathrm{y} \text { max }}$ of the yarn as illustrated in Figure 4 . In that case the ratio of matrix to fiber weight will increased, resulting in a lower value of $V_{\text {fcomp }}$. As indicated in Figure 10, the comparison of two cases specified the higher value of $V_{\text {fcomp }}$ when applying conditions given in Case I.

Yarn diameter data analysis are given in Table 3. demostrating that 
Comparison between case I and case II

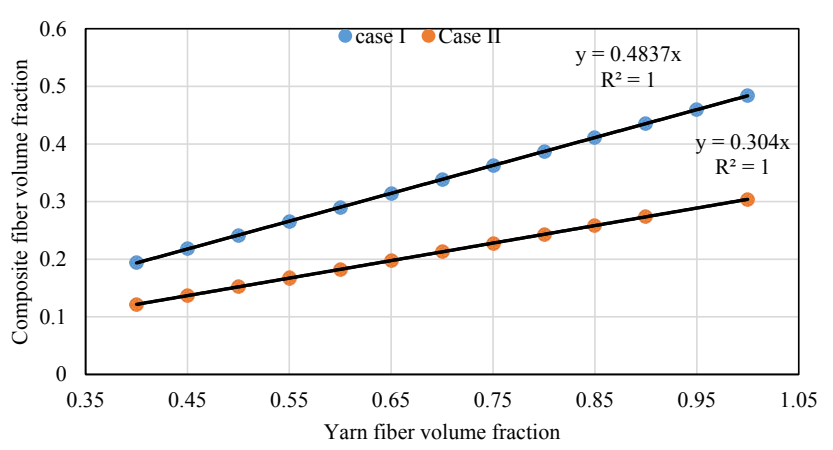

Figure 10: Comparison between composite fiber volume fraction and yarn fiber volume fraction in Case I and Case II.

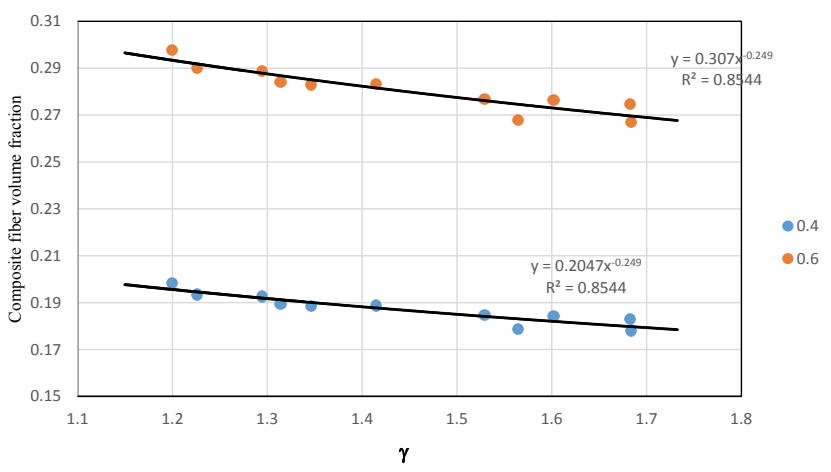

Figure 11: $V_{\text {fcomp }}$ versus $\gamma$.

\begin{tabular}{|l|l|l|l|l|l|l|}
\hline $\begin{array}{l}\text { Sample } \\
\text { ID }\end{array}$ & $\mathbf{D}_{\text {y.mean }}$ & $\mathbf{C V} \%$ & $\boldsymbol{\sigma}$ & $\begin{array}{l}\mathbf{D}_{\text {y.max }} \\
\mathbf{m m}\end{array}$ & $\mathbf{V}=\mathbf{D}_{\text {y.max } I} \mathbf{D}_{\mathbf{c}}$ & $\mathbf{D}_{\mathbf{c}}=\mathbf{X + 3 \sigma}$ \\
\hline 5394 & 0.328526 & 15.49357 & 0.0509 & 0.59 & 1.226 & 0.481 \\
\hline 6395 & 0.305499 & 14.51941 & 0.044357 & 0.57 & 1.300 & 0.439 \\
\hline 6396 & 0.172352 & 18.36763 & 0.031657 & 0.45 & 1.683 & 0.267 \\
\hline 6397 & 0.176745 & 15.97463 & 0.028234 & 0.44 & 1.683 & 0.261 \\
\hline 6398 & 0.176745 & 15.97463 & 0.028234 & 0.64 & 2.448 & 0.261 \\
\hline 6400 & 0.211491 & 16.33498 & 0.034547 & 0.66 & 2.094 & 0.315 \\
\hline 6409 & 0.305134 & 15.71713 & 0.047958 & 0.59 & 1.314 & 0.449 \\
\hline 215 & 0.216537 & 15.84439 & 0.034309 & 0.43 & 1.346 & 0.319 \\
\hline 216 & 0.321795 & 15.72429 & 0.0506 & 0.67 & 1.415 & 0.474 \\
\hline 217 & 0.326379 & 15.75656 & 0.051426 & 0.77 & 1.602 & 0.481 \\
\hline 218 & 0.280466 & 15.33761 & 0.043017 & 0.53 & 1.294 & 0.410 \\
\hline 219 & 0.314984 & 16.49429 & 0.051954 & 0.72 & 1.529 & 0.471 \\
\hline 220 & 0.305321 & 17.62183 & 0.053803 & 0.73 & 1.564 & 0.467 \\
\hline 221 & 0.27606 & 14.33111 & 0.039562 & 0.71 & 1.799 & 0.395 \\
\hline 222 & 0.271455 & 14.84114 & 0.040287 & 0.59 & 1.504 & 0.392 \\
\hline & & & & & \\
\hline
\end{tabular}

Table 3: Analysis of the yarn diameter for different samples.

ratio $\gamma=\left(\mathrm{D}_{y \text {. max }} \mathrm{D}_{\text {y. mean }}\right)$ related to the values of $V_{\text {fcomp }}$. As illustrated in Figure 11, it is proportional to the yarn diameter distribution kurtoses. Accordingly, it can be taken as a single variable to express the value $V_{\text {fcomp }}$ as given by Equation (6) for investigated data.

$$
\begin{gathered}
V_{f c o m p}=c^{-a} \\
V_{\text {fcomp }}=c \alpha \gamma^{-a} .
\end{gathered}
$$

Where: a, $c$ are constants depending on the variability of the yarn diameter cross section.

$$
V_{\text {fcomp }}=0.5135 \alpha \gamma^{-0.249}
$$

The value of $\gamma$ can be obtained directly from the data of measuring the yarn diameter by using Uster 4 tester which gives $\mathrm{D}_{\mathrm{y} \text {.max }}, \mathrm{D}_{\mathrm{y}^{\prime} \text { mean }}$ and $\mathrm{CV}_{\mathrm{y}} \%$. For continuous filament yarn, the values of constants a, $\mathrm{c}$ and $\gamma=1$ as given by Equation (4).

\section{Conclusion}

The fiber volume fraction plays an important role in the behavior of a composite under different loading. The quantity of fiber in a fiberreinforced composite directly relates to the mechanical properties of the composite. In the case of natural fiber polymer composites, the relation between $V_{\text {fcomp }}$ and $V_{\text {fyarn }}$ should be predetermined based on the above analysis and the equation giving to an engineer the required value of $V_{\text {fcomp }}$. It is recommended to use the yarns of low coefficient of variation and high $V_{f y a r n}$ which can be attained through an increase in the twist factor or use of the compact yarns. Another technique is to apply the pultrusion to the yarns that increases the composite fiber volume fraction.

\section{References}

1. Madsen B (2004) Properties of plant fiber yarn polymer composites: An experimental study. Technical university of Denmark.

2. Magdi El Messiry (2013) Theoretical analysis of natural fiber volume fraction of reinforced composites. Alexandria Engineering Journal 52: 301-306.

3. Thygesen A (2006) Properties of hemp fibre polymer composites. Ph.D. theses The Royal Agricultural and Veterinary University of Denmark.

4. Onal L, Karaduman Y (2009) Mechanical Characterization of Carpet Waste Natural Fiber-reinforced Polymer Composites. Journal of Composite Materials August 43: 1751-1768.

5. Lehtiniemi $P$, Dufva K, Berg T, Skrifvars M, Jarvela $P$ (2011) Natural fiberbased reinforcements in epoxy composites processed by filament winding Journal of Reinforced Plastics and Composites 30: 1947-1955.

6. Mehmood S, Madsen B (2012) Properties and performance of flax yarn/ thermoplastic polyester composites. Journal of Reinforced Plastics and Composites 31: 1746-1757.

7. Shah DU, Schubel PJ, Licence P, Clifford MJ (2012) Determining the minimum, critical and maximum fiber content for twisted yarn reinforced plant fiber composites. Composites Science and Technology 72: 1909-1917.

8. Ghosh R, Reena G, Krishna AR, Raju BHL (2011) Effect of fiber volume fraction on the tensile strength of Banana fibre reinforced vinyl ester resin composites. Int J Adv Eng Sci Technol 4: 89-91.

9. Shah DU, Schubel PJ, Clifford MJ, Licence P (2011) Mechanical characterization of vacuum infused thermoset matrix composites reinforced with aligned hydroxyethylcellulose sized plant bast fibre yarns. In: 4th International conference on sustainable materials, polymers and composites. Composites: Part A. Birmingham, UK.

10. Pan N (1993) Theoretical Determination of the Optimal Fiber Volume Fraction and Fiber-Matrix Property Compatibility of Short Fiber Composites. Polymer composites 14: 85-93.

11. Golzar M, Brunig H, Mader E (2007) Commingled Hybrid Yarn Diameter Ratio in Continuous Fiber-reinforced Thermoplastic. Journal of thermoplastic composite materials 20: 17-26.

12. Yilmaz D, Göktepe F, Göktepe O, Kremenakova D (2007) Packing density of compact yarns. Text Res J 77: 661-667.

13. Hao Ma, Yan Li, Di Wang (2014) Investigations of fiber twist on the mechanical properties of sisal fiber yarns and their composites. Journal of Reinforced Plastics and Composites 33: 687-696. 